\title{
Accuracy of Linear Measurements Before and After Digitizing Periapical and Panoramic Radiography Images
}

\author{
Caroline de Oliveira LANGLOIS ${ }^{1}$ \\ Maria Carméli Correia SAMPAIO ${ }^{2}$ \\ Alexandre Emidio Ribeiro SILVA ${ }^{3}$ \\ Nilza Pereira da COSTA ${ }^{4}$ \\ Maria Ivete Bolzan ROCKENBACH ${ }^{4}$
}

\begin{abstract}
${ }^{1}$ Department of Oral Radiology and Imaginology, Lutheran University of Brazil, Cachoeira do Sul, RS, Brazil ${ }^{2}$ Department of Dental Clinics and Community Dentistry, UFPB - Federal University of Paraiba, João Pessoa, PB, Brazil ${ }^{3}$ Department of Community Dental Health, Lutheran University of Brazil, Cachoeira do Sul, RS, Brazil ${ }^{4}$ Department of Surgery, Dental School, PUCRS - Pontifical Catholic University of Rio Grande do Sul,
\end{abstract} Porto Alegre, RS, Brazil

\begin{abstract}
The aim of this study was to evaluate the accuracy of linear measurements made on conventional and digitized periapical and panoramic radiographic images of dry human hemi-mandibles. Images from the posterior region of 22 dry human hemi-mandibles were obtained by conventional panoramic and periapical radiography technique. Using a digital caliper, 3 vertical measurements were marked directly on the dry hemi-mandibles (reference measurements) as well as on the tracing from the conventional radiographic images of the specimens made onto acetate paper sheet: Distance 1: between the upper limit of the alveolar ridge and the lower limit at the mandible base; Distance 2: between the upper limit of the alveolar ridge and the upper limit of the mandibular canal; Distance 3: between the lower limit of the mandibular canal and the lower limit of the mandible base. Next, the radiographs were digitized and the three measurements were made on the digital images using UTHSCSA Image Tool software. Data were analyzed statistically by one-way $\operatorname{ANOVA}(\alpha=0.05)$. There was no statistically significant differences $(p>0.05)$ between periapical and panoramic radiographs or between the measurements recorded using the digital caliper and UTHSCSA software compared with dry mandible specimens for Distances $1(p=0.783), 2(p=0.986)$ and $3(p=0.129)$. In conclusion, the radiographic techniques evaluated in this study are reliable for vertical bone measurements on selected areas and the UTHSCA Image Tool software is an appropriate measurement method.
\end{abstract}

Key Words: Dental radiography, panoramic radiography, software.

\section{INTRODUCTION}

The use of implants has reached a place of distinction in dentistry and provides a safe alternative for conventional prosthetic rehabilitations. Clinical success in oral rehabilitation depends on a thoroughly pre-surgery evaluation concerning implant location, which allows identifying possible bone alterations, location of anatomical structures, and support quality and amount of available bone tissue $(1,2)$.

Several imagining techniques have been investigated, ranging from conventional intraoral radiographs to the most advanced digital imaging methods, such as computed tomography (CT). Images generated either conventionally or digitally must allow acquiring measurements that reproduce the real conditions in order to determine whether there is sufficient alveolar bone structure for implant placement without causing damage to vital structures (3).

However, the sophisticated imaging systems are still restricted to large urban centers. The high cost of exams, the need of trained dentists for interpretation of complex images, and the elevated radiation dosages from CT procedures lead the surgeon to elaborate a clinical planning based on conventional radiographic images.

Among the options, periapical radiography has 
high resolution, is easily available, has low cost and is simple to handle. It provides a satisfactory relationship between film and long axis of the alveolar bone, with less amplification and distortion, being and important resource for analysis of anatomical structures.

The panoramic radiography is widely used for complementing surgical planning and diagnosis. It provides a wide observation of the maxillomandibular complex in a single film, at a lower cost and lower radiation dose than more sophisticated techniques, such as CT (4). Limitations of panoramic radiography are mainly related to the high distortion, two-dimensional view and the demand of previous training and knowledge to the magnification factor in order to avoid mistakes when measuring vertical bone dimensions.

Recently, specific software technology has facilitated measurement acquisition using digitized images of conventional radiographs. The use of software also allows manipulating images, storing them in compact discs, measuring both linear and angular distances and determining gray levels at a specific point, among other functions (5).

Much controversy exists concerning the reliability of panoramic and periapical radiographs, also becoming necessary a method of choice for safe evaluation. This study evaluated the accuracy of linear measurements made on conventional and digitized periapical and panoramic radiographic images of the posterior region of dry human hemi-mandibles to determine if digitization influences the obtained results. In addition, this study sought to estimate the precision of UTHSCSA Image Tool software to perform linear measurements.

\section{MATERIAL AND METHODS}

The study was conducted according to the ethical principles on human experimentation and was approved by the Health Sciences Center Ethics Committee (UFPB). Twenty-two human dry edentulous hemi-mandibles were used. The area of interest was the mandible body at $1.5 \mathrm{~cm}$ distal from the anterior limit of the mental foramen. This region was sectioned with a manual die saw at $90^{\circ}$ in relation to the mandible base and the fragments were joined with an adhesive band for subsequent examination.

Periapical images of the hemi-mandibles were obtained with the Spectro 70X x-ray unit (Dabi Atlante, Ribeirão Preto, SP, Brazil) operating at $70 \mathrm{kVp}$ and 8 $\mathrm{mA}$ with $0.4 \mathrm{~s}$ exposure time and $24 \mathrm{~cm}$ focal distance.
The film used was the Ultraspeed \#2 (Eastman Kodak Co, Rochester, NY, USA). For this technique, hemimandibles were fixed with utility wax at an acrylic plaque with the mandible basis parallel to the horizontal plan. A plastic film-holder designed by Berti (6) was used to obtain the parallelism of the film with the dry hemimandible. The film-holder consisted of 2 identical plastic blades ( $4.0 \mathrm{~cm}$ long, $3.0 \mathrm{~cm}$ wide and $2.0 \mathrm{~mm}$ thick), which form a $90^{\circ}$ angle between them, and a third blade $(2.0 \mathrm{~mm})$ fixed perpendicular to the horizontal blade for film positioning. The film was placed at the area of interest covering the entire area that was cut for mandible separation. Three images of each hemi-mandible were obtained 3 times, providing 66 radiographs. Radiograph processing was automatic (AT 2000 equipment; Air Techniques Co., Hicksville, NY, USA).

Panoramic radiographs were taken using the Orthophos CD x-ray unit (Siemens S.A., Berlin, Germany), in which each hemi-mandible was positioned with its base parallel to the ground and the midline coinciding with the equipment's led. Mandibles were fixed firmly to the chin support with a wax block to avoid any movement during exposure. The film used was the TMat G/RA(Eastman Kodak Co) and the equipment was adjusted at $60 \mathrm{kVp}$ and $9 \mathrm{~mA}$ with $8.1 \mathrm{~s}$ exposure time. Three images of each hemi-mandible were obtained 3 times, providing 66 radiographs.

It was possible to observe a radiolucent vertical line in the examined region of the radiographic images, corresponding to the previous cutting performed to obtain the hemi-mandibles (Fig. 1A and 1B). This line served as a reference for locating the area to be examined.

A magnifying lens was used to identify anatomic structures of interest and measure three linear distances in the panoramic and periapical radiographic images: Distance 1: between the upper limit of the alveolar ridge and the lower limit at the mandible base; Distance 2: between the upper limit of the alveolar ridge and the upper limit of the mandibular canal; Distance 3: between the lower limit of the mandibular canal and the lower limit of the mandible base. The structures were traced by a single examiner with a $0.3 \mathrm{~mm}$ pencil on acetate paper sheet (Ultraphan, St. Paul, MN, USA) and the distances were measured using a digital caliper (series 727; Starret, Itu, SP, Brazil), as indicated in the Figure $1 \mathrm{C}$ and $1 \mathrm{D}$.

The tracing on the periapical radiographs was measured without correction. The measures were corrected at 1.25 in their magnification according to 
the panoramic x-ray unit's manufacturer.

Using the same reference points established for the radiographic images, the measurements were repeated 3 times directly on the dry hemi-mandibles, using the digital caliper, and thereafter splitting the fragments previously joined with the adhesive band.

In order to perform measures using Image Tool version 3.00 (UTHSCSA, San Antonio, TX, USA), the panoramic and periapical radiographs were digitized with a flatbed scanner (HP Scanjet $6100 \mathrm{C} / \mathrm{T}$ scanner; Hewlett Packard Corp., Palo Alto, CA, USA) with 254 dpi resolution. The "Distance" tool was applied at the vertical radiolucent line in the images, corresponding to the cutting site on the dry specimens. This tool allowed determining 3 linear measurements in the images.

The 'space calibration' command was operated enabling the definition of a standard-measure for all 132 analyses. The panoramic radiography-magnifying factor determined by the x-ray unit's manufacturer was used for correction, as Image Tool software does not provide correction factors, which determine image magnifying degree. All measurements were made by a single calibrated operator.

From the 3 repetition values of each method - 1, 2 and 3 - average measurements were obtained on the conventional and digitized panoramic and periapical radiographs as well as on the dry specimens. One- way ANOVA was applied separately to each of the 3 measurements. The significance level was set at $5 \%$. The Percentage Variation Average (PVA) was also evaluated for each radiographic technique and measurement method in relation to the values recorded in the dry hemi-mandible.

$P V A=\underline{100 \times}($ dry hemi-mandible measurement $/$ method $)$ Dry hemi-mandible measurement

\section{RESULTS}

Considering the Distance 1 (distance between the upper limit of the alveolar ridge and the lower limit at the mandible base), Distance 2 (distance between the upper limit of the alveolar ridge and the upper limit of the mandibular canal) and Distance 3 (distance between the lower limit of the mandibular canal and the lower limit of the mandible base), no significant differences $(p>0.05)$ were observed between the values obtained in the dry hemi-mandibles and those recorded before and after digitization of the radiographic images (Table 1).

The PVA shows the difference, in percentage, between the evaluation method and the dry hemimandible measurement, which is the magnification degree obtained in the radiographic techniques. Conventional and digitized periapical radiographs, on
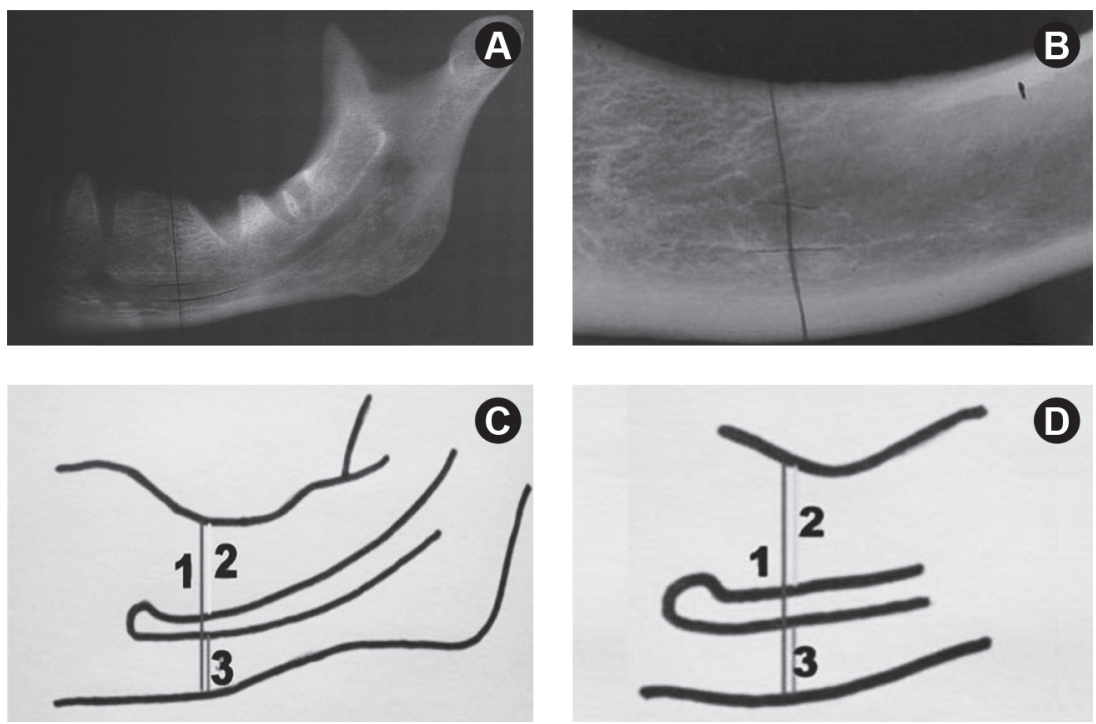

Figure 1. A- Panoramic radiograph of the selected region; B- Periapical radiograph of the selected region; C- Schematic illustration of measurements in the panoramic radiograph; D- Schematic illustration of measurement in the periapical radiograph. Distance 1= between the upper limit of the alveolar ridge and the lower limit at the mandible base; Distance $2=$ between the upper limit of the alveolar ridge and the upper limit of the mandibular canal; Distance $3=$ between the lower limit of the mandibular canal and the lower limit of the mandible base. 
Table 1. Means and standard deviations (in $\mathrm{mm}$ ) obtained with the radiographic techniques/measurement methods for the three distances.

\begin{tabular}{|c|c|c|c|}
\hline Distance & $\begin{array}{c}\text { Radiographic } \\
\text { technique/ } \\
\text { measurement method }\end{array}$ & Mean (SD) & $\begin{array}{c}\mathrm{p} \\
\text { value* }\end{array}$ \\
\hline \multirow{5}{*}{$\# 1$} & Dry specimens & $22.13(4.47)$ & \multirow{5}{*}{0.783} \\
\hline & Conv. PAR/caliper & $22.88(4.58)$ & \\
\hline & Conv. PNR/caliper & $21.62(4.30)$ & \\
\hline & Dig. PAR/Software & $22.58(4.57)$ & \\
\hline & Dig. PNR/Software & $21.38(4.42)$ & \\
\hline \multirow{5}{*}{$\# 2$} & Dry specimens & $12.06(4.59)$ & \multirow{5}{*}{0.986} \\
\hline & Conv. PAR/caliper & $12.55(4.67)$ & \\
\hline & Conv. PNR/caliper & $11.96(4.44)$ & \\
\hline & Dig. PAR/Software & $12.39(4.63)$ & \\
\hline & Dig. PNR/Software & $11.88(4.41)$ & \\
\hline \multirow{5}{*}{ \#3 } & Dry specimens & $7.12(1.10)$ & \multirow{5}{*}{0.129} \\
\hline & Conv. PAR/caliper & $7.13(1.08)$ & \\
\hline & Conv. PNR/caliper & $6.65(0.96)$ & \\
\hline & Dig. PAR/Software & $6.97(1.10)$ & \\
\hline & Dig. PNR/Software & $6.44(0.95)$ & \\
\hline
\end{tabular}

PAR = Periapical radiography; PNR = Panoramic radiography; *ANOVA and Tukey's test. average, overestimated dry hemi-mandible measurement by $3.9 \%$ and $2.3 \%$, respectively. Conversely, panoramic radiographs (conventional and digitized) underestimated the real values of the dry hemi-mandible by $2.1 \%$ and $3.4 \%$, respectively (Fig. 2).

\section{DISCUSSION}

The lack of significant differences between values obtained in the dry hemi-mandibles and those obtained before and after digitizing radiographic images for the three distances are in accordance with the experiments of others authors (4).

Radiographs taken from dry mandibles lead to superior results compared to the clinical situation (7). The accuracy in the present experiment could be reached due to the use of a dry hemi-mandible and a plastic film-holder for the radiographic film (6), manufactured and tested for laboratory studies whose purpose is to radiograph only dry hemi-mandible and to obtain the parallelism with the radiographic film. This fact permitted eliminating physical distortions in the film and standardization of periapical radiographs. It is possible that the lack of differences in results would not so evident in patients (8). In a clinical situation, periapical films are very difficult to be positioned exactly parallel to the mandible when the floor of the mouth is shallow, which may refrain the film to reach the mandibular canal, letting it out of the visualization area.

Even with no significant differences found between the methods, PVA calculation revealed that periapical radiography (conventional and digitized), on average, overestimated the actual measurements from dry hemi-mandible, while panoramic radiography (conventional and digitized) underestimated the real values. Larger distances than the real ones, measured in periapical radiographs have also been found by Sonick et al. (9), who identified magnification degrees between 8 and 24\% for the periapical radiograph. However, it is necessary to observe that such study used
Figure 2. Percentage average variation (PAV) in accordance to the radiographic method and to the type of inspection used in relation to the dry hemi-mandible measure. 
only one mandible, thus one image may not produce the same data variability.

The overestimation of real values of the anatomical specimen when using periapical radiography may be due to the use of the bisecting angle technique and not the paralleling technique. Paralleling technique prevents image distortions and provides more accurate linear measurements both in vertical and horizontal dimensions (10).

Wakoh et al. (11), when investigating implant length accuracy in periapical radiographs, observed that their precision were equivalent to measurements made on CT scans and even superior to them when located in the first molar region. We agree with the authors when reporting that standardized periapical radiographs may be used as a safe method for vertical linear distance measurements at the implant site.

Although Dharmar (1) mentions that due to the magnifying problems originated from the panoramic image, vertical measurements from the upper limit of the alveolar ridge until the upper limit of the mandibular canal are not reliable for selecting the exact implant lengths, this fact was not observed in the present study. The wide visualization of mandibular canal trajectory provided by this type of technique may be of great help for surgeons when choosing the appropriate implant if the radiograph magnification index is known in advance to the surgery. The greatest disadvantage of panoramic radiography is its insufficient resolution for anatomical details, which can be overcome by the use of complementary periapical radiographs (1).

In the present study, most measurements made on the panoramic radiographs were inferior than those recorded on the dry specimens. This results is in agreement with Klinge et al. (7) who found underestimated distance values between the upper limit of the alveolar ridge and the upper limit of the mandibular canal, obtaining lower magnification indexes than those informed by the manufacturers of x-ray units.

Distance overestimation between the upper limit of the alveolar ridge and the upper limit of the mandibular canal is a concerning fact because it could result in an implant insertion in the interior part of the nervous-vascular bundle causing paresthesia in the mental and superior lip region. On the other hand, the underestimation leads to the choice of a smaller implant than the ideal one, which may be an aggravating factor in treatment prognosis. However, although panoramic radiography may provide underestimated bone height values, underestimating is safer than overestimating due to the risk of reaching vital structures (7). Vazquez et al. (12) suggested the use of a $2 \mathrm{~mm}$ safe margin in the mental foramen region after the magnification image compensation when panoramic radiographs are used and Bahlis et al. (13) suggested the same safety margin for surgical purposes when using periapical radiographs.

The treatment plan for complex cases frequently requires radiographic techniques with a high dosage of exposure to the patient in order to provide the necessary information. In these cases, the use of conventional tomography or the $\mathrm{CT}$ is indispensable for selecting the appropriate implant height and avoid damage to vital anatomical structures $(14,15)$.

Simple cases, when an unique implant is necessary and where there is sufficient height and width of alveolar ridge, panoramic and/or periapical radiographs may form a good radiographic base for implants insertion in the posterior region of the mandible (10). Therefore, it is necessary to correlate radiographic findings with clinical data in other to avoid doubts related to the anatomical structure locations. Once carefully established the mandible height, the place for implant fixing can be safely determined.

Digital systems can make easier and more accurate quantitative measurements (16) and thus the evaluation of such programs is important, especially those available at no costs, such as the UTHSCSA Image Tool software.

Most studies present results comparing digital images with conventional radiographs (17-20). In a similar way, our findings indicated that the digitized images analyzed with UTHSCSA Image Tool software facilitated measurements. However, these images were as accurate as the inspected radiographs obtained by the conventional method. This indicates that digitized images may be used as an alternative resource for aiding the diagnosis. They make radiographic diagnostic process less subjective, as complementary resources may help with their interpretation. By using image manipulation procedures, such as altering contrast and brightness at specific areas (zoom), digital systems may offer additional and detailed information, thus optimizing results obtained by conventional techniques (16).

In conclusion, panoramic and periapical radiographic techniques are reliable for performing vertical linear measurements in the posterior region of the mandible, as there was no difference among the measurements obtained with conventional 
radiographs, digitized radiographs and dry specimen. In terms of difference degree between the evaluation method and the dry hemi-mandible, periapical radiography overestimated the measurements obtained in the anatomic specimen while panoramic radiography underestimated the values. Additionally, the UTHSCSA Image Tool software provided accurate results and can be considered as an appropriate method for measuring bone tissue in the studied region.

\section{RESUMO}

O objetivo deste estudo foi avaliar a acurácia de medidas lineares realizadas em radiografias panorâmicas e periapicais convencionais e digitalizadas de hemimandíbulas humanas secas. Imagens da região posterior de 22 hemimandíbulas humanas secas foram obtidas pelas técnicas panorâmica e periapical convencionais. Com o paquímetro eletrônico digital, foram realizadas três medições verticais diretamente sobre as hemimandíbulas (medidas referenciais), bem como sobre o decalque das imagens convencionais, em papel de acetato: Distância 1: Distância entre o limite superior do rebordo alveolar e o limite inferior da base da mandíbula; Distância 2: Distância entre o limite superior do rebordo alveolar e o limite superior do canal mandibular e Distância 3: Distância entre o limite inferior do canal mandibular e o limite inferior da base da mandíbula. Posteriormente, as radiografias foram digitalizadas e as três medidas foram realizadas nas imagens digitais utilizando o programa UTHSCSA Image Tool. Os dados foram analisados estatisticamente pelo teste ANOVA a um critério $(\alpha=0,05)$. Não houve diferenças estatisticamente significantes $(p>0,05)$ entre as radiografias panorâmicas e periapicais, assim como para as medidas obtidas com o paquímetro e pelo programa UTHSCSA Image Tool, quando comparados aos espécimes mandibulares, avaliando as distâncias $1(p=0,783), 2(p=0,986)$ e $3(p=0,129)$. Em conclusão, as técnicas radiográficas avaliadas neste estudo mostraram-se confiáveis para mensurações ósseas verticais na área selecionada e o programa de digitalização de imagens UTHSCSA Image Tool é um método adequado de aferição.

\section{REFERENCES}

1. Dharmar S. Locating the mandibular canal in panoramic radiographs. Int J Oral Maxillofac Implants 1997;12:113-117.

2. Mupparapu M, Singer S. Implant imaging for the dentist. J Can Dent Assoc 2004;70:32.

3. Peker I, Alkurt MT, Michcioglu T. The use of 3 different imaging methods for the localization of the mandibular canal in dental implant planning. Int J Oral Maxillofac Implants. 2008;23:463470.

4. Rockenbach MIB, Sampaio MCC, Costa LJ, Costa NP. Evaluation of mandibular implant sites: correlation between panoramic and linear tomography. Braz Dent J 2003;14:209-213.

5. Freitas DQ, Montebello Filho A. Evaluation of two methods of tracings for implants in panoramic radiographs. J Appl Oral Sci 2004;12:84-88.
6. Westphalen VPD, Moraes IG, Westphalen FH. Efficacy of conventional and digital radiographic imaging methods for diagnosis of simulated external root resorption. J Appl Oral Sci 2004; $12: 108-112$.

7. Klinge B, Petersson A, Maly P. Location of the mandibular canal: comparison of macroscopic findings, conventional radiography and computed tomography. Int J Oral Maxillofac Implants 1989;4:327332.

8. Gher ME, Richardson AC. The accuracy of dental radiographic techniques used for evaluation of implant fixture placement. Int $\mathrm{J}$ Periodontics Restorative Dent 1995;15:268-283

9. Sonick M, Abrahams J, Faiella RAA. Comparison of the accuracy of periapical, panoramic, and computed tomographic radiographs in locating the mandibular canal. Int J Oral Maxillofac Implants 1994;9:455-460.

10. Wyatt CCL, Pharoah MJ. Imaging techniques and image interpretation for dental implant treatment. Int J Prosthodont 1998;11:442-452.

11. Wakoh M, Harada T, Otonari T, Otonari-Yamamoto M, Ohkubo M, Housuge Y, et al.. Reliability of linear distance measurement for dental implant length with standardized periapical radiographs. Bull Tokyo Dent Coll 2006;47:105-115.

12. Vazquez L, Saulacic N, Belser U, Bernard JP. Efficacy of panoramic radiographs in the preoperative planning of posterior mandibular implants: a prospective clinical study of 1527 consecutively treated patients. Clin Oral Implants Res 2008;19:81-85.

13. Bahlis A, Mezzomo LA, Boeckel D, Costa NP, Teixeira ER. Accuracy of periapical radiography, panoramic radiography and computed tomography for examining the mental foramen region. Rev Odonto Ciênc 2010;25:282-287.

14. Mehra A, Pai KM. Evaluation of dimensional accuracy of panoramic cross-sectional tomography, its ability to identify the inferior alveolar canal, and its impact on estimation of appropriate implant dimensions in the mandibular posterior region. Clin Implant Dent Relat Res 2011 [Epub ahead of print. DOI:10.1111/ j.1708-8208.2009.00226.x.]

15. Angelopoulos C, Thomas SL, Hechler S, Parissis N, Hlavacek M. Comparison between digital panoramic radiography and cone-beam computed tomography for the identification of the mandibular canal as part of presurgical dental implant assessment. J Oral Maxillofac Surg 2008;66:2130-2135.

16. Pierro VSS, Souza IPR, Luiz RR, Barcelos R, Moraes RS. Reliability of two methods for measurement of alveolar bone level in children Dentomaxillofac. Radiol 2008;37:34-39.

17. Pecoraro M, Azadivatan-le N, Janal M, Khocht A. Comparison of observer reliability in assessing alveolar bone height on direct digital and conventional radiographs. Dentomaxillofac Radiol 2005;34:279-284.

18. De Smet E, Jacobs R, Gijbels F, Naert I. The accuracy and reliability of radiographic methods for the assessment of marginal bone level around oral implants. Dentomaxillofac Radiol 2002;31:176-181.

19. Kolltveit KM, Solheim T, Kvaal SI. Methods of measuring morphological parameters in dental radiographs. Comparison between image analysis and manual measurements. Forensic Sci Int 1998;94:87-95.

20. Yang HA, Yang Y, Wang HW, Meng QL, Ren XH, Liu YG. A comparative study of digital and anatomical techniques in skull base measurement. J Int Med Res 2010;38:78-85.

Received July 20, 2010 Accepted August 4, 2011 